\title{
The Relationship between Migration and Economic Growth ${ }^{\dagger}$
}

\author{
- In a Closed and an Open Economy _-
}

\author{
Hideto AzEGAMI*
}

\begin{abstract}
This paper explores the long-run economic growth and labor migration in the process of economic development. We adopt the dual economy model in which there exist two production parts; manufacturing and agriculture. In the case of closed economy, two production parts remain and the labor allocation is constant along the equilibrium path. If the economy participates in the international commodity market, the equilibrium path leads it to complete specialization. Rural (agricultural) to urban (manufacturing) migration continues until the stock of capital reaches a certain level. After the agricultural sector vanishes, the GDP grows at a constant rate that is higher than that in the closed economy.
\end{abstract}

\section{Introduction}

All the developed countries experienced decrease in agricultural labor force while they were developing into the industrialized economies. In Japan, for instance, more than $50 \%$ of the labor force engaged in agriculture on the early stage of economic development but it decreased to $4.9 \%$ in $1998^{1}$. Such a change in the industrial structure with decrease in agricultural labor force was often explained in "dual economy" models that were a subclass of two-sector models of growth ${ }^{2}$. Lewis [9] (1954), Jorgenson [8] (1961), and Harris and Todaro [7] (1970) are the typical studies. The Harris-Todaro model explains the persistence of rural to urban migration in the presence of urban unemployment and its crucial assumption is that the industrial (urban) wage is institutionally fixed. Beladi and Marjit [3] (1996) and Bencivenga and Smith [4] (1998) are recent studies based on the Harris-Todaro migration model. While labor is only factor of production in Harris and Todaro [7] (1970), Beladi and Marjit [3] (1996) assume that manufacturing product is produced with capital as well as labor. But capital accumulation is not supposed because of static framework. Bencivenga and Smith [4] (1998) combine a Harris-Todaro migration model with a model of economic growth. They demonstrate that migration and urban underemployment can be a source of development traps. On the other hand, Mas-Colell and Razin [10] (1973) analyze rates of growth of migration and a policy of subsidy-tax in a neoclassical growth model without unemployment. Like these studies, it is plausible that rural (agriculture) to urban (manufacturing) migration is caused by wage differences between two sectors. Such a labor allocation mechanism is also introduced in this paper but there is neither unemployment nor

\footnotetext{
${ }^{\dagger}$ I would like to thank T. Asada, L. Lundqvist, and two anonymous referees for helpful comments and suggestions. I am, of course, responsible for any remaining errors.

* Department of Economics, Kanto Gakuen University

1 Data are taken from Ministry of Labor, Japan [10] (1998).

2 A comprehensive survey of dual economy models is in Basu [1] (1997, Part III).
} 
redundant labor. We shall assume that the agricultural productivity of labor is constant over time and households inelastically supply labor to industrial firms if the wage rate they offer is not less than the agricultural productivity measured in manufacturing commodity.

In contrast to these classical or neoclassical approaches, endogenous growth models, in which the long-run rate of economic growth is endogenously determined, have been studied for the last two decades. Matsuyama [11] (1992) examined the role of agricultural productivity in economic development. The result is that there is a positive link between agricultural productivity and economic growth in the closed economy model but there is a negative link in the open economy model. It crucially depends on the assumption that the income elasticity of demand for agricultural commodity is less than unity. Our result is different from it because demand elasticity for all commodities is unity in our model.

Although there are several types of endogenous growth models ${ }^{3}$, we adopt a specific Romer model, in which sustainable growth arises from a positive capital externality (Romer [14] (1986)). The production function depends not only on firm-specific inputs but on the level of aggregate (average) stock of capital in the economy since the stock of capital is regarded as a proxy for knowledge. In several studies this type of production function is represented as an AK technology in equilibrium, which implies that output is proportion to the aggregate stock of capital. With the AK technology Wu and Zhang [15] (1998) examine the welfare costs of inflation and Osang and Turnovsky [13] (2000) analyzes the effects of consumption and investment tarrifs on growth and welfare. These models are rather simple compared with other types of endogenous growth models, e.g. R \& D model in which technological progress is regarded as increase in the number of types of products (Grossman and Helpman [6] (1991) or as improvements in the quality of products (Aghion and Howitt [1] (1992)). But we adopt the AK technology because of its tractability. We shall show that there exist a balanced growth path in the closed economy model and an equilibrium path on which the industry completely specializes in manufacturing in the small open economy model.

The plan of this paper is as follows. Section 2 presents the economic environment and the equilibrium path in the closed economy model. Section 3 turns to the small open economy model. Section 4 offers some concluding remarks.

\section{The closed economy}

\subsection{The Environment}

Consider a representative agent model with no foreign trade in this section. There exist two production parts in the economy; manufacturing sector and agricultural sector. There are $m(>0)$ homogenous firms in the manufacturing sector and a representative firm produces $x_{M}(t)$ units of the manufacturing commodity as of time $t$, which are consumed or invested. The production technology is given by the Cobb-Douglas function;

(1) $x_{M}(t)=k(t)^{\alpha} n_{M}(t)^{1-\alpha} K(t)^{1-\alpha}, \quad 0<\alpha<1$,

where $k(t)$ is the stock of capital employed by an individual firm, $n_{M}(t)$ is the demand of

${ }^{3}$ See Chari, Jones, and Manuelli [4] (1995) for classification of endogenous growth models. 
labor, and $K(t)$ is the aggregate stock of capital in the economy, so that $K(t)=m k(t)$. Eq. (1) implies that the production function is homogeneous of degree one in $k(t)$ and $n_{M}(t)$, and so in $k(t)$ and $K(t)$. But the aggregate stock of capital $K(t)$ is exogenous to each firm and it captures the external effects of knowledge accumulation ${ }^{4}$. Since it is assumed that the capital market is competitive, profit maximization behavior of each firm induces Eq.(2) ;

(2) $r(t)=\alpha k(t)^{\alpha-1} n_{M}(t)^{1-\alpha} K(t)^{1-\alpha}$,

where $r(t)$ denotes the rental price of capital.

There are also $h(>0)$ homogenous households and they produce agricultural products at their family farms. A representative household consists of $N$ members of workers and each of them inelastically supplies one unit of labor services per unit of time. Abstracting from the issue of population growth, $N$ is constant over time. $n_{A}(t)$ of those $N$ members reside in the rural area and cultivate their own land to produce $x_{A}(t)$ units of agricultural commodity. Its technology is given by the linear production function;

(3) $x_{A}(t)=A n_{A}(t), \quad 0 \leq n_{A}(t) \leq N$,

where $A$ denotes agricultural productivity, which may reflect the level of technology, the fertility of the soil, and climate, among other things. It is constant over time and treated as an exogenous parameter. Each household also provides labor force to manufacturing firms, so that the rest of the members, $N-n_{A}(t)$, reside in the urban area to earn the wages $w(t)(N$ $-n_{A}(t)$ ), where $w(t)$ denotes the real wage rate measured in manufacturing commodity.

Let $p(t)$ denote the relative price of agricultural commodity. Then labor income and sales of agricultural commodity that each household obtains as of time $t$ becomes $w(t)(N$ $\left.-n_{A}(t)\right)+p(t) x_{A}(t)=w(t)\left(N-n_{A}(t)\right)+p(t) A n_{A}(t)$. When she intends to maximize her income, all the members of household move to the urban (rural) area if the wage rate is higher (lower) than the real agricultural productivity. If both are at the same level, the labor allocation is not determined. To avoid this matter, we assume that households provide their labor to satisfy aggregate labor demand of all firms if the wage rate is not less than the real agricultural productivity, otherwise they provide no labor to firms. This is formally stated in Assumption 1.

\section{Assumption 1. \\ If $w(t)<p(t) A$, then $h\left(N-n_{A}(t)\right)=0$. \\ If $w(t) \geq p(t) A$, then $h\left(N-n_{A}(t)\right)=m n_{M}(t)$.}

Although each firm offers the wage rate so low as to make its profit as big as possible, it cannot employ any labor if the wage rate is lower than the real agricultural productivity. Thus the wage rate is equalized to the real agricultural productivity;

(4) $w(t)=p(t) A$.

The labor demand of each firm is lead from its profit maximization behavior; $p(t) A=$

4 Romer [14] (1986) originated this type of externality. The Cobb-Douglas function is a sufficient condition for the economy to follow a balanced growth path ; see Chari, Jones, and Manuelli [5] (1995) and $\mathrm{Wu}$ and Zhang [15] (1998). 
$\partial\left(k(t)^{\alpha} n_{M}(t)^{1-\alpha} K(t)^{1-\alpha}\right) / \partial n_{M}(t)$. On account of this equation it is given by Eq.(5).

(5) $\quad n_{M}(t)=\left[\frac{(1-\alpha) k(t)^{\alpha} K(t)^{1-\alpha}}{p(t) A}\right]^{\frac{1}{\alpha}}$

Eq.(5) determines the labor allocation of each household, namely,

(6) $\quad n_{A}(t)=N-\frac{m}{h}\left[\frac{(1-\alpha) k(t)^{\alpha} K(t)^{1-\alpha}}{p(t) A}\right]^{\frac{1}{\alpha}}$.

Household's instantaneous utility function is given by $\theta \ln c_{M}(t)+(1-\theta) \ln c_{A}(t),(0<\theta<$ 1) where $c_{M}(t)$ and $c_{A}(t)$ denote consumption of the manufacturing commodity and the agricultural commodity as of time $t$. Since each firm offers the wage rate under the Eq.(4), household's labor income plus sales of agricultural commodity is $p(t) A N$. Further, she also obtains income from interests for her savings, which are in the form of capital. Let $a(t)$ be the capital stock that she rents to firms as of time $t$. Her intertemporal utility maximization problem is formulated as follows.

$$
\begin{aligned}
& \max _{c_{M}(t), c_{A}(t), a(t)} \int_{0}^{\infty}\left\{\theta \ln c_{M}(t)+(1-\theta) \ln c_{A}(t)\right\} e^{-\rho t} d t \\
& \text { s.t. } \quad \dot{a}(t)=r(t) a(t)+p(t) A N-c_{M}(t)-p(t) c_{A}(t),
\end{aligned}
$$

where $\rho$ is the subjective discount rate assumed to be strictly positive. The necessary conditions are Eq.(7) and Eq.(8), and the transversality condition is Eq.(9).

(7) $\theta / c_{M}(t)=(1-\theta) /\left(p(t) c_{A}(t)\right)$

(8) $\quad \dot{c}_{M}(t) / c_{M}(t)=r(t)-\rho$

(9) $\lim _{t \rightarrow \infty} \frac{a(t)}{c_{M}(t) e^{\rho t}}=0$

\subsection{Dynamic system of the economy}

Before characterizing the dynamic system of the economy, some more technical assumptions are given. Since households are homogeneous in this model, the number of them can be normalized to unity, that is, $h=1$. Therefore the population of this economy is $N\left(=n_{M}(t)\right.$ $\left.+n_{A}(t)\right)$. The number of firms is normalized to unity as well ; $m=1$. This normalization implies that the individual capital stock is equivalent to the aggregate capital stock in the economy. In addition, as household's assets consist of capital only, it is clear that $K(t)=$ $a(t)=k(t)$ for all $t \geq 0$.

The dynamic system of the economy is lead from Eqs.(2), (5), (7), (8), and market-clearing conditions. The market-clearing condition for agricultural commodity is $p(t) x_{A}(t)=$ $p(t) c_{A}(t)$. Substituting $c_{A}(t)=A n_{A}(t)$ into Eq.(7) and using $n_{A}(t)=N-n_{M}(t)$ yield $\theta / c_{M}(t)=$ $(1-\theta) /\left(p(t) A\left(N-n_{M}(t)\right)\right)$. Using this equation and Eq.(5), we can eliminate the relative price $p(t)$, that is,

$$
n_{M}(t)^{\alpha}=\frac{\xi\left(N-n_{M}(t)\right) k(t)}{c_{M}(t)}
$$

where $\xi=\theta(1-\alpha) /(1-\theta)$. Eq.(10) is solved for the manufacturing labor as a function of capital stock and manufacturing consumption. Let $n(v(t))$ be the solution of Eq.(10), where 
$v(t) \equiv c_{M}(t) / k(t)$. It is easy to make sure that $n^{\prime}(v(t))<0^{5}, \lim _{v(t) \rightarrow 0} n(v(t))=N$, and $\lim _{v(t) \rightarrow+\infty}$ $n(v(t))=0$. Since the demand of manufacturing commodity consists of consumption and savings, the market-clearing condition is expressed as $\dot{k}(t)+c_{M}(t)=x_{M}(t)$. This equation induces the differential equation with respect to the stock of capital ;

(11) $\dot{k}(t) / k(t)=n(v(t))^{1-\alpha}-v(t)$,

where $v(t)=c_{M}(t) / k(t)$. Finally, Eq.(2) is written as $r(t)=\alpha n(v(t))^{1-\alpha}$. Substituting this into Eq.(8) yields the differential equation with respect to manufacturing consumption;

(12) $\quad \dot{c}_{M}(t) / c_{M}(t)=\alpha n(v(t))^{1-\alpha}-\rho$.

Eqs.(11) and (12) represent the dynamic system of the economy ${ }^{6}$. Even if the initial value of capital stock is historically given, various solution paths exist for the choice of initial value of manufacturing consumption. An equilibrium path is defined as a set of solutions that satisfy the transversality condition and are economically feasible. The transversality condition Eq.(9) is now rewritten as Eq.(13).

(13) $\lim _{t \rightarrow \infty} \frac{1}{v(t) e^{\rho t}}=0$.

It is useful to depict a phase diagram to characterize the equilibrium path. Figure 1 shows that there exists a unique balanced growth path (BGP) on which the capital stock and manufacturing consumption are increasing at the equivalent rate. Without any additional assumptions, however, it is not guaranteed that the balanced growth rate is strictly positive. A sufficient condition to positive growth rate is that the subjective discount rate is not so large. In other words, $\rho$ has an upper bound ${ }^{7}$.

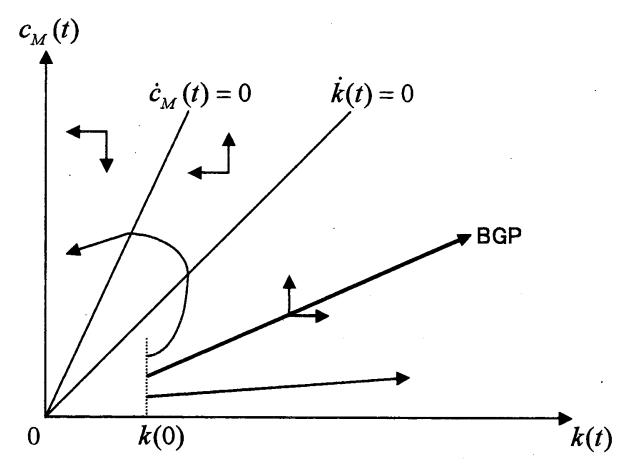

Figure 1.

5 Eq.(10) is written as $n_{M}(t)^{\alpha}=\xi\left(N-n_{M}(t)\right) / v(t)$. By differentiating this with respect to $n_{M}$ and $v$, we get $\left.\alpha n_{M}{ }^{\alpha-1} d n_{M}=-(\xi / v) d n_{M}-\xi\left(N-n_{M}\right) / v^{2}\right) d v$. Therefore $d n_{M} / v d=-\xi\left(N-n_{M}\right) /\left(v^{2}\left(\alpha n_{M}{ }^{\alpha-1}+\xi\right)\right)<0$, that is, $n^{\prime}(v(t))<0$.

${ }^{6}$ Eq.(11) is also induced from household's budget constraint, the market-clearing condition of agricultural commodity, and $a(t)=k(t)$. Thus the dynamic system is consistent with the budget constraint of household, namely Walras' law holds in this economy.

7 Calculation of the value is in Appendix A. 


\section{Assumption 2.}

The subjective discount rate $\rho$ satisfies the following inequality.

$$
\rho<\alpha\left[\frac{\xi}{1+\xi} N\right]^{1-\alpha}
$$

The balanced growth implies $\dot{k}(t) / k(t)=\dot{c}_{M}(t) / c_{M}(t)$. Let $\hat{v}$ be a value of $v(t)$ that satisfies this equation, that is, $\hat{v}-(1-\alpha) n(\hat{v})^{1-\alpha}-\rho=0$. Hence, the balanced growth rate is $\alpha n(\hat{v})^{1-\alpha}$ $-\rho$, or equal to $n(\hat{v})^{1-\alpha}-\hat{v}$. For any initial level of capital stock the economy can be on the balanced growth path by choosing an appropriate initial value of manufacturing consumption $^{8}$. In fact the balanced growth path is a unique equilibrium path ${ }^{9}$. Formally,

\section{Proposition 1.}

Under Assumption 2, there exists a balanced growth path in the economy and it is a unique equilibrium path. Along the equilibrium path, the capital stock, manufacturing consumption, manufacturing products, and the relative price are increasing at the balanced growth rate, $\alpha n(\hat{v})^{1-\alpha}-\rho$. On the other hand, the labor allocation does not change and the agricultural products are constant over time.

This proposition is interpreted as follows. Regardless of the initial level of the capital stock, the economy can be on a balanced growth path. Manufacturing products are expanding along the path with increase of capital stock. Although real agricultural products are constant over time, their nominal value is rising at the balanced growth rate due to the rise of the relative price. Since it is assumed that migration does not take any time, the labor allocation is constant on the balanced growth path. Even if the manufacturing labor is small in the beginning of economic development, workers instantly move to the urban area and supply labor to satisfy the labor demand of the firm. It is plausible that both sectors perpetually remain in equilibrium because the utility function is defined as a log-linear function and there is no foreign trade.

Specialization may occur if foreign trade is allowed. The small open economy is examined in the next section.

\section{The small open economy}

The existence of the balanced growth path crucially depends on the closed economy assumption. To see the possibility of specialization, imagine a small open economy. While both commodities are tradable, labor is immobile across countries and international borrowing and lending are not permitted. Because the economy is too small to affect the international commodity markets, the relative price of agricultural commodity is exogenously given and assumed to be constant over time; $p(t)=p>0$ for all $t \geq 0$. Thus, Eq.(4) turns into Eq. (14).

(14) $w(t)=p A$ for all $t \geq 0$

8 If $k(0)=k_{0}>0$ is given, $c_{M}(0)$ is chosen as $c_{M}(0)=k_{0} \hat{v}$.

9 This is proved in Appendix B. 
Eq.(14) shows that the wage rate is always fixed. Further, on account of Eq.(5), it is clear that the labor allocation depends only on the capital stock, that is, the manufacturing labor in equilibrium is an increasing function of capital stock. This implies that all the workers may move to the urban area with high capital accumulation. Now, the manufacturing labor is given by

$$
\left\{\begin{array}{l}
n(t)=\left[\frac{1-\alpha}{p A}\right]^{\frac{1}{\alpha}} k(t)^{\frac{1}{\alpha}}, \text { for } 0 \leq k(t)<\bar{k} \\
n(t)=N, \text { for } \bar{k} \leq k(t)
\end{array}\right.
$$

where $\bar{k}=\frac{p A}{1-\alpha} N^{\alpha}$. Let us call $\bar{k}$ the specialization level of capital stock. If the capital stock exceeds it, the industry specializes in manufacturing. The dynamic system of the economy must be examined in two cases viz. there are two production parts in the economy and the industry specializes in manufacturing.

\section{2-sector economy}

Since household's utility maximization problem does not change, Eqs.(7) through (9) do not change either. Supply and demand of each commodity need not equilibrate here but the current account must be balanced ; $x_{M}(t)-c_{M}(t)-\dot{k}(t)=p\left(c_{A}(t)-x_{A}(t)\right)$. Eq.(16) is straightforward from this.

(16) $\dot{k}(t)=k(t) n(t)^{1-\alpha}+p A(N-n(t))-\left(c_{M}(t)+p c_{A}(t)\right)$

Substituting Eq.(15) into Eq.(16) and using Eq.(7) yield the differential equation with respect to capital stock ;

$$
\dot{k}(t)=\frac{\alpha p A}{1-\alpha}\left[\frac{1-\alpha}{p A}\right]^{\frac{1}{\alpha}} k(t)^{\frac{1}{\alpha}}-\frac{c_{M}(t)}{\theta}+p A N, \quad 0 \leq k(t)<\bar{k}
$$

On the other hand the differential equation with respect to manufacturing consumption is induced from Eqs.(2), (8), and (15).

$$
\dot{c}_{M}(t)=\left\{\alpha\left[\frac{1-\alpha}{p A}\right]^{\frac{1-\alpha}{\alpha}} k(t)^{\frac{1-\alpha}{\alpha}}-\rho\right\} c_{M}(t), \quad 0 \leq k(t)<\bar{k}
$$

The dynamic system represented by Eqs.(17) and (18) has an unstable steady state ${ }^{10}$. Although it seems that the steady state value of capital stock, $\frac{p A}{1-\alpha}\left(\frac{\rho}{\alpha}\right)^{\frac{\alpha}{1-\alpha}}$ exceeds the specialization level, the former is exactly lower than the latter ${ }^{11}$ by virtue of Assumption 2 .

\section{1-sector economy}

Consider the economy in which production part consists of manufacturing sector only.

\footnotetext{
${ }^{10}$ Let $\tilde{k}$ and $\tilde{c}_{M}$ denote the steady state values of capital stock and manufacturing consumption, respectively. The linear approximation of the system around the steady state is expressed as $\left(\begin{array}{c}\dot{k}(t) \\ \dot{c}_{M}(t)\end{array}\right)=L\left(\begin{array}{c}k(t)-\widetilde{k} \\ c_{M}(t)-\tilde{c}_{M}\end{array}\right)$, where $L \equiv\left(\begin{array}{cc}\rho /(\alpha \phi A) & -1 / \theta \\ \rho(1-\alpha) \tilde{c}_{M} /(\alpha \tilde{k}) & 0\end{array}\right)$. Since trace $|L|>0$ and $\operatorname{det}|L|>0$, the steady state is unstable.

${ }^{11}$ By Assumption 2, $\rho<\alpha\{\xi N /(1+\xi)\}^{1-\alpha}<\alpha N^{1-\alpha}$.
} 
The dynamic system of the economy is induced from substituting $n_{M}(t)=N$ into the equations in the previous section and the Eq.(16). Differential equations with respect to capital stock and manufacturing consumption are Eqs.(19) and (20), respectively.

$$
\begin{aligned}
& \dot{k}(t)=k(t) N^{1-\alpha}-\frac{c_{M}(t)}{\theta}, \quad \bar{k} \leq k(t) \\
& \dot{c}_{M}(t)=\left(\alpha N^{1-\alpha}-\rho\right) c_{M}(t), \quad \bar{k} \leq k(t)
\end{aligned}
$$

It is clear that this system has a balanced growth path and it is a unique equilibrium path. Moreover, this balanced growth rate is higher than that in the closed economy because it is clear that $\alpha N^{1-\alpha}-\rho>\alpha n(\hat{v})^{1-\alpha}-\rho$. Although there are no agricultural products in this economy, the agricultural consumption is increasing at the rate along the path. Hence, the path is named one-sector balanced growth path (1-BGP).

\section{migration}

In general, there is a little capital accumulation at an initial stage of economic development. Our model describes the transitional dynamics that a country switches over from 2sector economy to 1-sector economy. The phase diagram for the dynamic systems given by Eqs.(17)-(18) and Eqs.(19)-(20) is illustrated in Figure $2^{12}$.

If an initial value of capital stock is given lower than the specialization level, there is at least one initial value of manufacturing consumption that leads the economy to the onesector balanced growth path. Figure 2 shows that the capital stock may decrease for a while after the household chooses a high initial level of manufacturing consumption ${ }^{13}$. Migration from urban (manufacturing) to rural (agriculture) continues while the capital stock is decreasing. Yet, if the economy is on the path that eventually reaches the one-sector

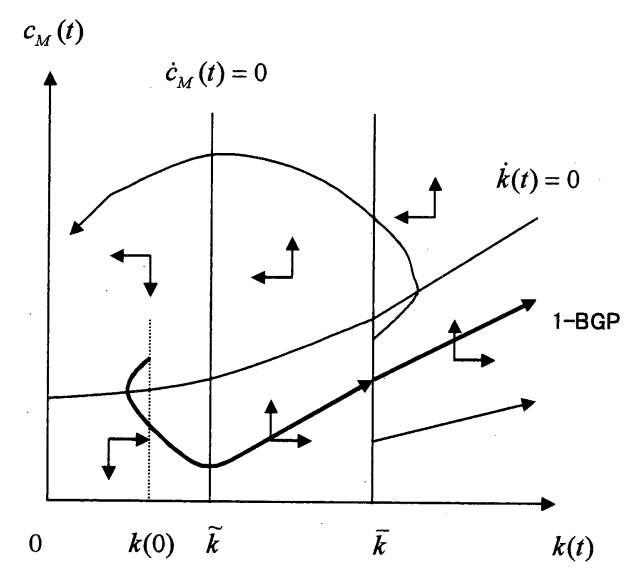

Figure 2.

${ }^{12}$ Appendix $\mathrm{C}$ shows that the phase diagram is depicted as Figure 2 under Assumption 2 and all the paths except one that reaches the 1-BGP are not equilibrium paths.

${ }^{13}$ From Eq.(7), this implies that she also chooses a high initial level of agricultural consumption. In other words, if people enjoy high level of consumption in the beginning, they must experience recession for some time. 
balanced growth path, the economic growth and rural to urban migration occur ${ }^{14}$. The quantitative influence caused by the change of the relative price or agricultural productivity is obvious. The rise of either parameter causes the high specialization level of capital stock. Of course, when the specialization level of capital stock is infinite, the agricultural sector eternally remains. Such a situation can happen if the marginal productivity of labor increases without bound as agricultural labor force approaches zero, say $\lim _{n_{A} \rightarrow 0}\left(d x_{A} / d n_{A}\right)=+\infty$. In our model, however, the industry completely specializes in manufacturing in equilibrium since the production technology of agriculture is assumed to be linear. The results are stated in Proposition 2.

\section{Proposition 2.}

In the case of small open economy there exists an equilibrium path that leads the economy to specialization. Under Assumption 2 the steady state value of capital stock is lower than specialization level. If a low level of initial capital stock is given and the household chooses the appropriate initial level of consumption, the capital stock continues to grow with rural to urban migration. After the economy reaches the one-sector balanced growth path, the manufacturing products increase at the constant rate that is greater than that in the closed economy.

\section{Concluding remarks}

The purpose of this paper has been to examine the relationship between migration and economic growth in two polar cases of the closed economy and small open economy. In the case of closed economy, the capital stock, manufacturing products, manufacturing consumption, and the relative price of agricultural commodity were growing at the equivalent rate along the equilibrium path. But the real products of agriculture maintained a certain level because of the constant labor allocation. In the case of small open economy, however, migration was persistent until the industry specialized in manufacturing because manufacturing labor was an increasing function of the capital stock. After the agricultural sector vanished, the economy grew at the rate that was higher than that in the closed case.

This result is not surprising because the closed economy is considered as a restricted version of the small open economy. Nevertheless we cannot neglect the fact that the open economy might experience the recession in the early stage of economic development. It was a period when consumption of both commodities and manufacturing products declined. Since there was transitional dynamics in the case of small open economy, it was not obvious whether the welfare in the small open economy was exactly higher than in the closed economy even if the former was less restricted than the latter.

Finally the weak influence of agricultural productivity on the behavior of economy should be improved in another study. Although the specialization level in the case of small open economy was positively related to the agricultural productivity, the long-run growth

\footnotetext{
${ }^{14}$ Since the equilibrium path is unstable, government intervention, for instance, may be meaningful if there are exogenous shocks that make the economy deviate from the path. Several other modifications of the model are possible.
} 
rate was independent of the agricultural productivity in both cases.

\section{Appendices}

\section{Appendix A}

Since the $\hat{v}$ satisfies $\hat{v}-(1-\alpha) n(\hat{v})^{1-\alpha}-\rho=0$, it is solved with respect to $\rho$. If we denote the solution by $\hat{v}(\rho), \hat{v}^{\prime}(\rho)>0$ is obvious. Hence, the balanced growth rate, $n(\hat{v}(\rho))^{1-\alpha}-\hat{v}(\rho)$, or equal to $\alpha n(\hat{v}(\rho))^{1-\alpha}-\rho$ is a decreasing function with respect to $\rho$. Suppose the balanced growth rate is zero if $\rho=\bar{\rho}$, that is, $n(\hat{v}(\bar{\rho}))^{1-\alpha}-\hat{v}(\bar{\rho})=\alpha n(\bar{v}(\bar{\rho}))^{1-\alpha}-\bar{\rho}=0$. From these equations, it is clear that $\hat{v}(\bar{\rho})=\bar{\rho} / \alpha$ and $n(\hat{v}(\bar{\rho}))=(\bar{\rho} / \alpha)^{1 /(1-\alpha)}$. Substituting these into the Eq.(10) yields an equation with respect to $\bar{\rho}$ and it is solved as $\bar{\rho}=\alpha\{\xi N /(1+\xi)\}^{1-\alpha}$. The balanced growth rate is zero or negative if $\rho \geq \bar{\rho}$. Therefore $\bar{\rho}$ is an upper bound of subjective discount rate.

\section{Appendix B}

For any initial value of capital stock $k_{0}>0$, which is historically given, a pair of sequences $\left\{\hat{k}(t), \hat{c}_{M}(t)\right\}_{t=0}^{\infty}$ is a balanced growth path if and only if $\hat{c}_{M}(0)$ is chosen as $\hat{c}_{M}(0)=$ $k_{0} \hat{v}$, where $\hat{v} \equiv\left\{v \mid \hat{v}-(1-\alpha) n(\hat{v})^{1-\alpha}-\rho=0\right\}$. This is proved as follows.

[1] $c_{M}(0)<k_{0} \hat{v}$

In this case, $v(0)=c_{M}(0) / k_{0}<\hat{v}$ is straightforward. Since $\dot{v}(t) / v(t)$ is increasing in $v(t)$ due to $n^{\prime}(v(t))<0$ and $\dot{v}(t) / v(t)=\dot{c}_{M}(t) / c_{M}(t)-\dot{k}(t) / k(t)=\left(\alpha n(v(t))^{1-\alpha}-\rho\right)-\left(n(v(t))^{1-\alpha}\right.$ $-v(t))=v(t)-(1-\alpha) n(v(t))^{1-\alpha}-\rho$, it is clear that $\dot{v}(t) / v(t)<0$ for all $t \geq 0$. Therefore, $|\dot{v}(t) / v(t)|-\rho=(1-\alpha) n(v(t))^{1-\alpha}-v(t)$ and there exists a $t_{0} \in(0,+\infty)$ such that $|\dot{v}(t) / v(t)|$ $-\rho>0$ for all $t \geq t_{0}$. This implies that the transversality condition is violated because $\lim _{t \rightarrow \infty}$ $\left(1 /\left(v(t) e^{\rho t}\right)\right)=\infty$.

[2] $c_{M}(0)>k_{0} \hat{v}$

Taking into account the fact in [1], we can find that $\dot{v}(t) / v(t)>0$ for all $t \geq 0$ and $\lim _{t \rightarrow \infty}$ $v(t)=\infty$ because $\frac{d}{d t}\left(\frac{\dot{v}(t)}{v(t)}\right)=\left[1-(1-\alpha)^{2} n(v(t))^{-\alpha} n^{\prime}(v(t))\right] \dot{v}(t)>0$. Therefore $\lim _{t \rightarrow \infty} \frac{\dot{c}_{M}(t)}{c_{M}(t)}=$ $\lim _{t \rightarrow \infty}\left[\alpha n(v(t))^{1-\alpha}-\rho\right]=-\rho<0$. As the utility function is a log-linear function, the utility diverges due to zero consumption of manufacturing commodity.

[3] $c_{M}(0)=k_{0} \hat{v}$

From the definition of $\hat{v}$ it follows that $\hat{k}(t) / \hat{c}_{M}(t)$ is constant over time, so $\lim _{t \rightarrow \infty} \frac{\hat{k}(t)}{\hat{C}_{M}(t) e^{\rho t}}$ $=0$ is straightforward. Thus $\left\{\hat{k}(t), \hat{c}_{M}(t)\right\}_{t=0}^{\infty}$ is a unique equilibrium path.

\section{Appendix C}

[1] We show that the $\dot{k}(t)=0$ locus is located above the 1-BGP in Figure 2.

For $k(t) \geq \bar{k}, \dot{k}(t)=0$ locus and the 1-BGP are both straight lines and their equations in the $\left(k, c_{M}\right)$ plane are $c_{M}(t)=\theta N^{1-\alpha} k(t)$ and $c_{M}(t)=\theta\left[(1-\alpha) N^{1-\alpha}+\rho\right] k(t)$, respectively. Using the inequality in Assumption 2, we can derive $N^{1-\alpha}=(1-\alpha) N^{1-\alpha}+\alpha N^{1-\alpha}>(1-\alpha) N^{1-\alpha}$ 
$+\alpha\left[\frac{\xi}{1-\xi} N\right]^{1-\alpha}>(1-\alpha) N^{1-\alpha}+\rho . \quad$ Then $\theta N^{1-\alpha} k(t)>\theta\left\lfloor(1-\alpha) N^{1-\alpha}+\rho\right\rfloor k(t)$ for every $k(t) \geq$ $\bar{k}$.

[2] All the paths located below the 1-BGP violate the transversality condition.

If $k\left(t_{0}\right) \geq \bar{k}$ is given for some $t_{0} \geq 0$, then for all $t \geq t_{0}$ inequalities $\dot{k}(t) / k(t)>\dot{c}_{M}(t) / c_{M}(t)$ $>0$ hold on the paths located below the 1-BGP and $\dot{k}(t) / k(t)-\dot{c}_{M}(t) / c_{M}(t)-\rho=N-\alpha N^{1-\alpha}$ $-c_{M}(t) /(\theta k(t))$ is straightforward from Eqs.(19) and (20). Since there exists a $t_{1} \geq t_{0}$ such that $N-\alpha N^{1-\alpha}-c_{M}(t) /(\theta k(t))>0$ for all $t>t_{1}$, the fraction $\frac{k(t)}{c_{M}(t) \exp [\rho t]}$ does not converge to zero as $t$ goes to infinity.

[3] All the paths located above the 1-BGP lead the economy back to 2-sector economy.

[1] shows that the gradient of $\dot{k}(t)=0$ locus is $\theta N^{1-\alpha}$, which is constant. On the other hand, the gradient of a path passing through the area bounded by three lines; $\dot{k}(t)=0$ locus, $1-\mathrm{BGP}$, and $k(t)=\bar{k}$, is given by $\dot{c}_{M}(t) / \dot{k}(t)=\frac{\left(\alpha N^{1-\alpha}-\rho\right) c_{M}(t) / k(t)}{N^{1-\alpha}-c_{M}(t) /(\theta k(t))}$. This is increasing in time $t$ in the area and exceeds the gradient of $\dot{k}(t)=0$ locus $\theta N^{1-\alpha}$ because an inequality $\dot{k}(t) / k(t)<\dot{c}_{M}(t) / c_{M}(t)$ holds there. Since $\dot{c}_{M}(t)$ is strictly positive if $k(t)>\bar{k}$, every path in the area necessarily crosses the $\dot{k}(t)=0$ locus. Since $\dot{k}(t) / k(t)$ is strictly negative in the area above $\dot{k}(t)=0$ locus, there exists a $t_{2}<\infty$ and $k(t)$ becomes smaller than $\bar{k}$ for all $t \geq t_{2}$ on every path passing through the area.

\section{References}

[1] Aghion, P. and P. Howitt, "A model of growth through creative destruction," Econometrica Vol. 60, No. 2, March 1992, pp. 323-351.

[2] Basu, K., Analytical development economics, The MIT Press, 1997.

[ 3 ] Beladi, B. and S. Marjit, "An analysis of rural-urban migration and protection," Canadian Journal of Economics Vol. 29, No. 4, November 1996, pp. 930-940.

[4 ] Bencivenga, V.R. and B.D. Smith, "Unemployment, Migration, and Growth," Journal of Political Economy Vol. 105, No. 3, 1998, pp. 582-608.

[5] Chari, V.V., L.E. Jones, and R.E. Manuelli, "The growth effects of monetary policy," Federal Reserve Bank of Minneapolis Quarterly Review Vol.19, No. 4, Fall 1995, pp. 18-32.

[6] Grossman, G. and E. Helpman, Innovation and Growth in the Global Economy, The MIT Press, 1991.

[ 7 ] Harris, J.R. and M.P. Todaro, "Migration, unemployment and development: a two-sector analysis," American Economic Review Vol. 60, No. 1, March 1970, pp. 126-142.

[ 8 ] Jorgenson, D.W., "The development of a dual economy," Economic Journal Vol. 71, 1961, pp. 309334.

[9] Lewis, W.A., "Economic development with unlimited supplies of labour," Manchester School of Economics and Social Studies Vol. 22, 1954, pp. 139-191.

[10] Mas-Colell, A. and A. Razin, "A model of intersectoral migration and growth," Oxford Economic Papers, 1973, pp. 72-79.

[11] Matsuyama, K., "Agricultural productivity, comparative advantage, and economic growth," Journal of Economic Theory Vol. 58, 1992, pp. 317-334.

[12] Ministry of labour, Year book of labour statistics, Vol. 51, Policy Planning and Research Department, Minister's Secretariat, Japan, 1998.

[13] Osang, T. and S.J. Turnovsky, "Differential tariffs, growth, and welfare in a small open economy," 
Journal of Development Economics Vol. 62, 2000, pp. 315-342.

[14] Romer, P.M., "Increasing returns and long-run growth," Journal of Political Economy Vol. 94, No. 5, 1986, pp. 1002-1037.

[15] Wu, Y. and J. Zhang, "Endogenous growth and the welfare costs of inflation : a reconsideration," Journal of Economic Dynamics and Control Vol. 22, 1998, pp. 465-482. 